\section{References}

Crawhall, J. C., and Watts, R. W. E. (1968). Cystinuria. American Journal of Medicine, 45, 736-755.

Dahlberg, P. J., Van Den Berg, C. J., Kurtz, S. B., Wilson, D. M., and Smith, L. H. (1977). Clinical features and management of cystinuria. Mayo Clinic Proceedings, 52, 533-542.

Macdonald, W. B., and Fellers, F. X. (1968). Quantitative measurement of cystine in urine. American Journal of Clinical Pathology, 49, 123-126.
Stokes, G. S., Potts, J. T., Jr, Lotz, M., and Bartter, F. C. (1968). New agent in treatment of cystinuria: N-acetylD-penicillamine. British Medical Journal, 1, 284-288.

Terhorst, B., and Stuhlsatz, H. W. (1975). Cystinsteintherapie mit Mercaptopropyonylglycin (MPG) (Thiola). Urologe; Ausgabe A, 14, 190-193.

Correspondence to Dr G. Ruysch van Dugteren, Renal Clinic, Red Cross War Memorial Children's Hospital, Rondebosch 7700, Cape Town, South Africa.

\title{
Takayasu's arteritis as a differential diagnosis of systemic juvenile chronic arthritis
}

\author{
EVE ROSSOR
}

Department of Paediatrics, Northwick Park Hospital, Harrow

SUMMARY After a series of throat infections an 8-year-old girl presented with fever and limb pain, initially diagnosed as juvenile chronic arthritis. Persistent symptoms led to further investigations when she was shown to have an arteritis affecting her aorta.

As there are no specific diagnostic tests for juvenile chronic arthritis (JCA), a remittent fever with a high swinging pattern associated with limb pain which continues for at least 2 weeks tends to be regarded as systemic JCA. However, a number of conditions, including various types of arteritis, can also produce these symptoms (McEnery, 1977).

\section{Case report}

An 8-year-old Yugoslavian girl was referred for advice on further management of what was thought to be systemic JCA of 18 months' duration. She was the only child of healthy unrelated parents and had been well until age 7 when, during a 4-month period, she had four episodes of pyrexia to $38^{\circ} \mathrm{C}$ associated with pharyngitis, which were treated with ampicillin. She subsequently developed fever with a temperature which characteristically reached $40^{\circ} \mathrm{C}$ daily between the afternoon and midnight, and then subsided spontaneously. She was generally unwell with considerable pain in her lower limbs, but no other signs or symptoms. Initial investigations showed ESR $97 \mathrm{~mm}$ in 1st hour, Hb $9.9 \mathrm{~g} / \mathrm{dl}$, WBC $13.0 \times 10^{9} / 1$, a hypercellular bone marrow, and ASO titre $<1 / 200$; blood cultures and all other investigations were negative. Skin and muscle biopsies were normal. She was given a 10-day course of lincomycin and gentamicin but her fever persisted; there was transient improvement with salicylate. Prednisolone was started at an initial dosage of $\mathbf{8 0}$ mg daily with pronounced improvement in ESR and fever. Both these parameters deteriorated when prednisolone was reduced to $10 \mathrm{mg}$ daily. She was continued on $10 \mathrm{mg}$ prednisolone daily and aspirin until referred here one year later.

When seen she still had an occasional fever, despite the prednisolone and aspirin. She was markedly cushingoid, and was on the 50th centile for height and the 90th centile for weight. There were no specific complaints but on direct questioning she did admit to some lower abdominal pain, discomfort in the calf muscles, and bleeding haemorrhoids. There were 4 small café-au-lait spots but no other cutaneous lesions. There was no lymphadenopathy, rash, hepatosplenomegaly, or arthritis. Her pulses were easily palpable in the arms and carotids, but no pulses were felt in the femoral arteries or in the legs, which were cold and hairless. No bruit was heard. Blood pressure was $130 / 80 \mathrm{mmHg}$ in the arms and, by Doppler, $90 / 0 \mathrm{mmHg}$ in the legs. All other systems were normal apart from first-degree haemorrhoids. Some days after examination it became obvious that the pain in the calves was, in fact, intermittent claudication as it appeared to be closely associated with the child walking some $300-400$ metres.

\section{Investigations}

ESR was raised at 57 rising to $88 \mathrm{~mm}$ in 1st hour on reduction of prednisolone, $\mathrm{Hb} 12 \cdot 2 \mathrm{~g} / \mathrm{dl}$, WBC 
$12 \cdot 3 \times 10^{9} / 1-61 \%$ neutrophils, $32 \%$ lymphocytes, $6 \%$ monocytes, $1 \%$ eosinophils; IgA $4 \cdot 4 \mathrm{~g} / 1$ (normal $0 \cdot 5-2 \cdot 3 \mathrm{~g} / \mathrm{l}$ ), IgM $2 \cdot 6 \mathrm{~g} / 1$ (normal $0 \cdot 5-2 \cdot 0 \mathrm{~g} / \mathrm{l}$ ), IgG $10 \cdot 4 \mathrm{~g} / \mathrm{l}$ (normal); Clq immune complexes were not detected in the serum, complement was normal, renal function was normal. Ultrasound showed an obstruction above the bifurcation of the aorta. Aortography was characteristic of Takayasu's arteritis of type II. There was narrowing of the thoracic aorta associated with a saccular aneurysm (Fig. 1) with incomplete occlusion of the abdominal aorta below the renal arteries and well formed collaterals (Fig. 2).

\section{Management}

In view of the already serious involvement of the aorta with persisting disease activity as judged by fever, ESR, and raised immunoglobulins, it was considered justifiable to give cytotoxic treatment. Chlorambucil $0 \cdot 15 \mathrm{mg} / \mathrm{kg}$ was added to the regimen of prednisolone at $10 \mathrm{mg}$ on alternate days. After 14

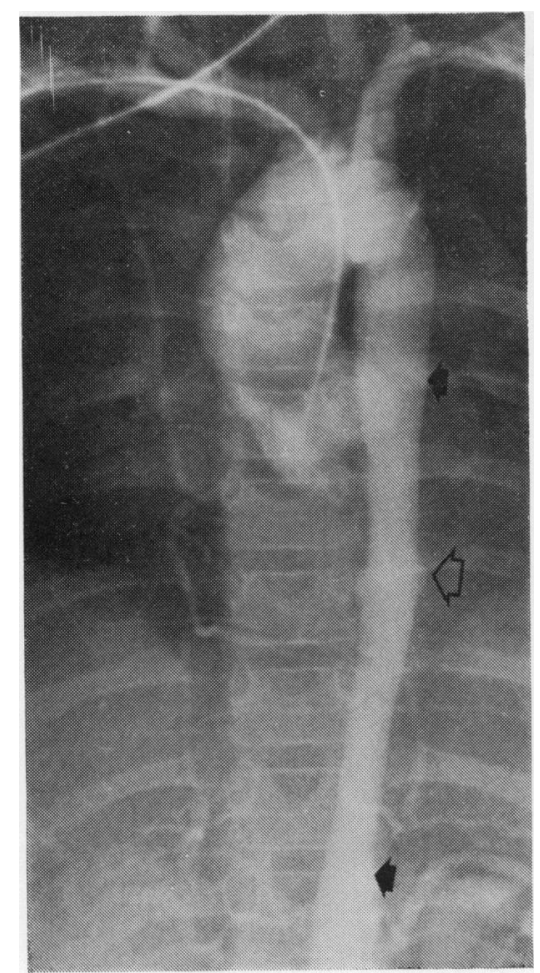

Fig. 1 Thoracic aortogram. The descending thoracic aorta is diffusely narrowed over a long segment (closed arrows). A small saccular aneurysm is noted (open arrow). All the great vessels are present.

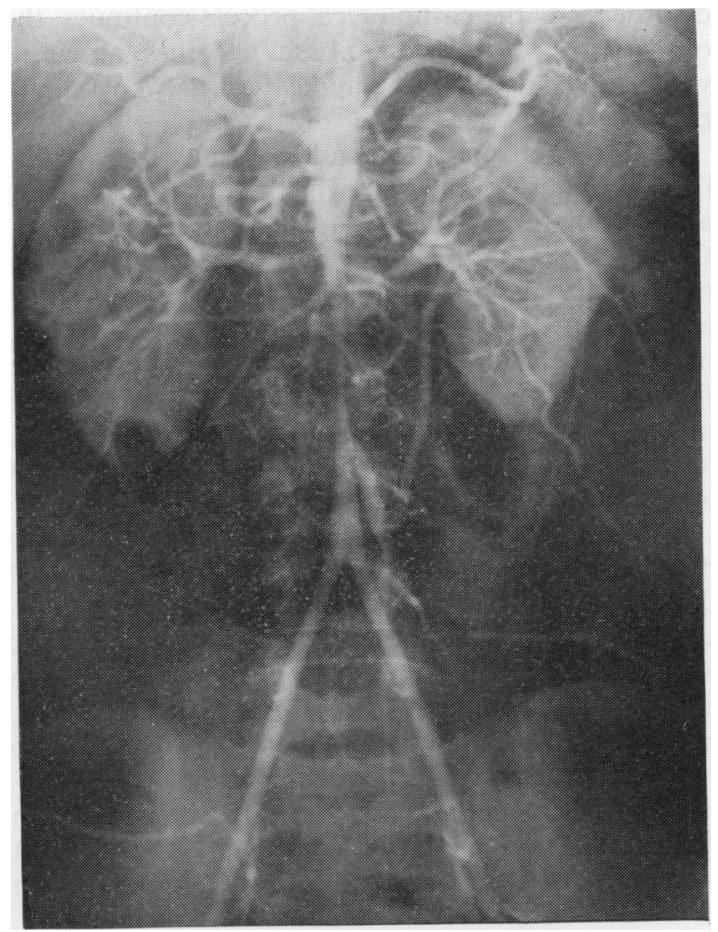

Fig. 2 Abdominal aortogram. A long segment of the abdominal aorta is diffusely narrowed. Good flow to the iliac arteries is established through mesenteric collaterals.

days of this regimen, the ESR had subsided to $31 \mathrm{~mm}$ in 1st hour and the child was apyrexial. She returned home and has continued to do well.

\section{Discussion}

Takayasu's arteritis is a rare inflammatory disorder affecting the aorta and large arteries in a patchy distribution. It occurs predominantly in females in the 2 nd and 3 rd decade, although there are several reports of cases presenting in childhood (Lupi Herrera et al., 1977). The pathogenesis is uncertain but autoimmune and infectious causes have been suggested. The pathological changes consist of inflammation in all layers of the wall of the aorta with pronounced intimal thickening. Fibrosis occurs with subsequent narrowing and occlusion of the lumen, and aneurysm formation at weaker areas.

Strachan (1964) has divided the disease process into an acute systemic or prepulseless phase, and a chronic pulseless phase. The systemic phase, which may last for a period of months or years (Strachan et al., 1966), is manifested by a raised ESR and a variety of symptoms suggesting connective tissue 
disorders. As the pathological process continues, the obstructive or pulseless phase becomes apparent with symptoms such as claudication, weakness, and parasthesiae.

Definitive diagnosis is made at either stage of the illness by arteriography which shows narrowing and/or dilatation of the aorta and its branches. Constrictions of the aorta may be short and segmental or long and diffuse, the latter being common in children in whom the abdominal aorta is often involved. Lande and Rossi (1975) suggested that in this age group the fibrosis limits the growth potential of the aorta, which can then not expand normally, leading to narrowing of the vessels with persistent and often increasing claudication.

The role of corticosteroids and immunosuppressive drugs in treatment of Takayasu's arteritis is not well defined although several reports suggest corticosteroids may prevent progression (Kawai et al., 1978). Should activity not be controlled, particularly in children, in view of a possible aorta growth problem, cytotoxic drugs should be added in an attempt to reduce destruction by the inflammatory process.

This case re-emphasises the need for caution in diagnosing systemic JCA, particularly when joint involvement is inconspicuous. Better identification of the limb pain as ischaemic rather than myositic or arthralgic would have led to earlier diagnosis of the disease process in this case.

I thank Dr R. Wilkins, for performing the aortogram, and Dr B. M. Ansell for permission to describe this case.

\section{References}

Kawai, C., Ishikawa, K., Kato, M., Ishii, Y., and Nakao, K. (1978). Clinical conference in cardiology. Pulmonary pulseless disease; pulmonary involvement in so-called Takayasu's disease. Chest, 73, 651-657.

Lande, A., and Rossi, P. (1975). The value of aortography in the diagnosis of Takayasu's arteritis. Radiology, 114, 287-297.

Lupi Herrera, E., Sanchez Torres, G., Marcushamer, J., Mispireta, J., Horwitz, S., and Espinovela, J. (1977). Takayasu's arteritis. Clinical study of 107 cases. American Heart Journal, 93, 94-103.

McEnery, G. (1977). Giant cell arteritis with gangrene in a child. Archives of Disease in Childhood, 52, 733-735.

Strachan, R. W. (1964). The natural history of Takayasu's arteriopathy. Quarterly Journal of Medicine, 33, 57-69.

Strachan, R. W., Wigzell, F. W., and Anderson, V. R. (1966). Locomotor manifestations and serum studies in Takayasu's arteriopathy. American Journal of Medicine, 40, 560-568.

Correspondence to Dr Eve Rossor, Department of Paediatrics, Northwick Park Hospital, Harrow, Middlesex HA1 3UJ. 